\title{
Type 1 (insulin-dependent) diabetes in Japanese children is not a uniform disease
}

\author{
T. Urakami, Y. Miyamoto, H. Fujita and T.Kitagawa \\ Department of Pediatrics, Nihon University, School of Medicine, Tokyo, Japan
}

\begin{abstract}
Summary. The initial course of Type 1 (insulin-dependent) diabetes mellitus was studied in two groups of Japanese children, i.e. 21 patients with abrupt onset (Group A) and 19 patients detected by urine glucose screening at school with minimal or no symptoms (Group B). There was no statistical difference in mean age at diagnosis between Group A and B ( $11 \pm 3$ years vs $11 \pm 3$ years). Group A patients revealed a rapid deterioration of pancreatic B-cell function, but there was evident recovery of the B-cell function from 3 to 9 months following initial treatment. The B-cell capacity in Group B was self maintained until 24 months after diagnosis. Thereafter, even these patients exhibited a progressive decline in the B-cell function. The two groups had a similar incidence of islet
\end{abstract}

cell antibodies at diagnosis ( $58 \%$ vs $69 \%$ ). However, human leukocyte antigen studies revealed that patients in Group A had a significantly higher prevalence of DR4 and DRW9 than those in Group B $(p<0.01)$. These results suggest that in Japanese children there are two forms of diabetes, an abrupt and a slow onset form, which are clinically different and which also seemed to be genetically indeplendent types, or possibly the same disease diagnosed at different stages.

Key words: Type 1 (insulin-dependent) diabetes in Japan, urine glucose screening, human leukocyte antigen, abrupt onset form, slow onset form.
Previous reports have shown that juvenile onset Type 1 (insulin-dependent) diabetes mellitus in Caucasian, African and Mediterranean populations have typical clinical symptoms of diabetes and their B-cell function is completely deteriorated or absent at the time of diagnosis $[1,2]$. However, some recent reports have indicated that in some patients with juvenile onset Type 1 diabetes, the disease is of a progressive nature, and the patients continue to display some evidence of residual B-cell activity during the first years of diabetes [3-5]. In Japan, we have observed a number of Type 1 diabetic children with minimal or no symptoms of diabetes who were detected by chance during urine glucose screening at school $[6,7]$. In the present study, we have examined 21 children with Type 1 diabetes with abrupt onset and 19 children with Type 1 diabetes detected by urine glucose screening at school. The purpose of the present study was to find out whether the two forms of diabetes in Japanese children were two different types of diseases, or the same disease diagnosed at different stages.

\section{Subjects and methods}

The study was comprised of 40 children, 18 males and 22 females, aged 7 to 15 years at the time of diagnosis. The patients were diagnosed as Type 1 diabetes during the period from 1974 to 1986 in Tokyo, Japan. We divided them into two sub-groups, i.e. Group A $(n=21)$ representing those children with the abrupt onset form with clinical symptoms and Group B $(n=19)$ with minimal or no clinical symptoms, who were detected by urine glucose screening at school. Urine glucose screening was instituted in 1974 for school children re siding in Tokyo to detect diabetes. During the period from 1974 through 1986, we annually examined approximately $225,000-386,400$ school children, and all 18 Type 1 diabetes and 106 Type 2 (non-insulin-dependent) diabetes were detected by the urine glucose screening. Our screening procedure is as follows: urinalysis was carried out using glucose oxidase tapes on a morning urine specimen. If a positive result was obtained, a subsequent urine test was requested on another morning. The oral glucose tolerance test (OGTT) was performed on those subjects who revealed a positive result in both the initial and the second test. In the OGTT $1.75 \mathrm{~g} / \mathrm{kg}$ (maximum $75 \mathrm{~g}$ ) of glucose was used and the U.S. Public Health Service criteria was used for the diagnosis of diabetes. Type 2 diabetes usually displayed relatively high insulin response to OGTT. In general, Type 1 diabetes detected by urine glucose screening showed low insulin reaction to OGTT. In some cases, however, it seemed difficult to make a distinc- 


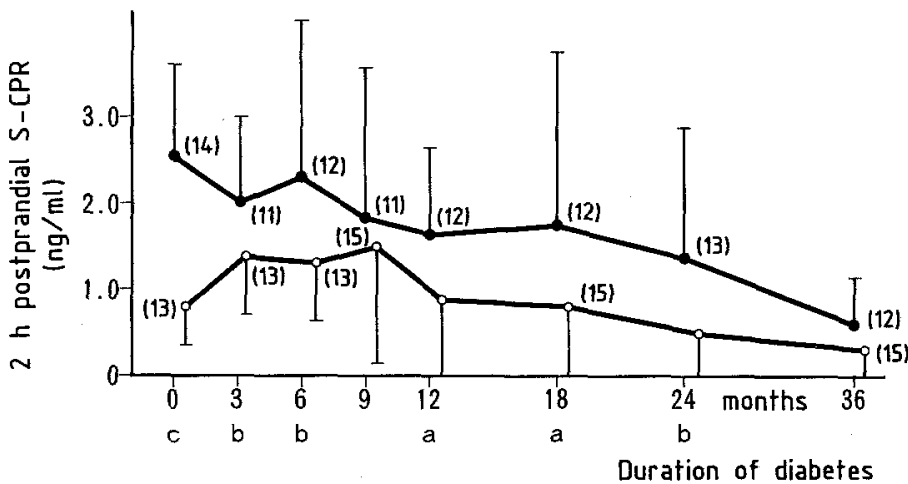

Fig. 1. Serial $2 \mathrm{~h}$ postprandial S-CPR values during the first three years of diabetes in groups $A(O)$ and $B(-)$. The results at each period were expressed as mean $\pm \mathrm{SD}$. Statistical differences of values among the two groups are expressed at bottom of figure (a: $p<0.05$, b: $p<0.025$, c: $p<0.01$ ). Numbers in parentheses indicate the number of patients studied

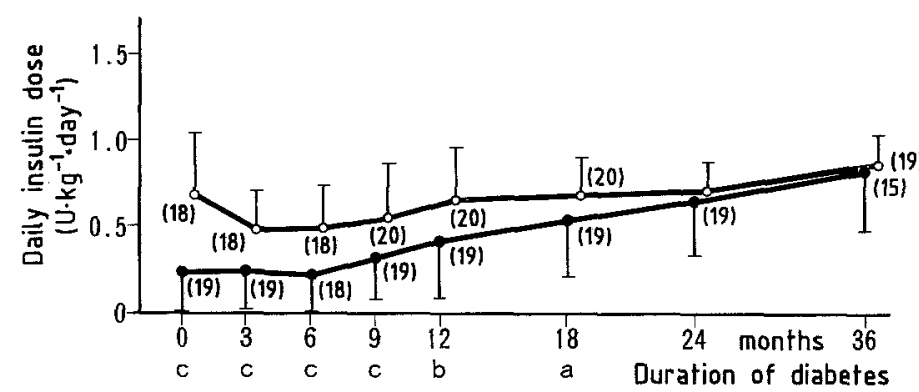

Fig. 2. Serial insulin dosages during the first three years of diabetes in groups $A(O)$ and $B(O)$. The results at each period were expressed as mean \pm SD. Statistical differences of values among the two groups are expressed at bottom of figure (a: $p<0.05, \mathrm{~b}: p<0.025, \mathrm{c}: p<0.01$ ). Numbers in parentheses indicate the number of patients studied

tion between Type 1 and Type 2 diabetes merely on the basis of insulin secretion ability at the time of diagnosis. Hence, several months or more observation of glucose intolerance and pancreatic B-cell faculties was required in such cases to define the type of diabetes. Children with Type 1 diabetes detected by urine glucose screening usually failed to improve their glucose tolerance in spite of strict dietary control and physical exercise, and they required insulin therapy for their glycaemic control within at least 18 months after diagnosis.

Blood glucose level was measured by a glucose oxidase method. $\mathrm{HbA}_{1 \mathrm{c}}$ value was measured by a high-performance liquid chromatography method (normal range: 5.5 to $7.0 \%$ ). Serum C-peptide (S-CPR) and immunoreactive insulin were measured by radioimmunoassay using two antibodies. Human leukocyte antigen (HLA) typing was performed by a standard microcytotoxicity test [8]. Islet cell antibodies (ICA) were determined by an indirect immunofluorescence technique on cryostat section of human blood group 0 pancreas, with the kind collaboration of Dr. Noel K. Maclaren, University of Florida, Gainesville, Florida, USA [9].

\section{Statistical analysis}

Statistical comparisons of the data were analysed by Student's $t$-test and the $\chi^{2}$ test. Correlations were performed by linear regression analysis. The results were expressed as mean \pm SD.
Results

Patients' characteristics at diagnosis (Table 1)

The pertinent clinical data of the two patient groups at diagnosis are shown in Table 1. Group A patients with abrupt onset of diabetes consisted of 12 males and 9 females, and Group B patients detected by urine glucose screening at school consisted of 6 males and 13 females. Predominance of females was distinct in Group B contrary to that of Group A $(p=0.105)$.

The mean age at diagnosis of Group A was $11 \pm 3$ years (7-15 years), and that of Group B was $11 \pm 3$ years ( $6-15$ years). There was no statistical difference in ages between the two groups at diagnosis.

With regard to the clinical features at diagnosis, 16 patients $(76 \%)$ had ketonuria and six patients $(29 \%)$ had impaired consciousness out of the 21 patients in Group A. On the other hand, all the patients in Group B showed minimal or no clinical symptoms of diabetes. In the family history of Group B patients, two Type 2 diabetic patients were noted. The mean value of $\mathrm{HbA}_{1 \mathrm{c}}$ was significantly lower $(p<0.025)$ and the mean concentration of S-CPR was significantly higher $(p<0.01)$ in Group B at diagnosis. In addition, Group B patients required significantly less insulin for initial treatment to achieve normalisation of the metabolic derangement.

\section{Changes of $2 h$ postprandial S-CPR levels and daily insulin dosages during the first 3 years}

As shown in Figure 1, Group B patients maintained significantly higher S-CPR values than patients in Group A until 24 months after diagnosis $(p<0.025)$. However, at the time of 36 months after diagnosis, there was no statistical difference of S-CPR values between the two groups.

There was an evident recovery of pancreatic B-cell function (post-initial remission period) from 3 to 9 months following treatment in most of Group A patients. However, after this period, they lost their B-cell faculties in a relatively short term. Although Group B patients showed a higher value of S-CPR at diagnosis, their B-cell capacities gradually declined.

Serial insulin dosages between the two groups are shown in Figure 2. At the time of diagnosis, the mean insulin requirement of Group A was significantly higher than that of Group B. All the patients in Group A required insulin injections once or twice daily from onset of diabetes. Six out of 19 patients $(32 \%)$ in Group B did not require insulin treatment at diagnosis to improve their metabolic derangement. However, all the patients in Group B received insulin injections once or twice daily within 18 months after diagnosis to control their blood glucose levels. 
Following diagnosis, Group B patients were controlled by significantly lower insulin dosages than Group A patients until 18 months after diagnosis $(p<0.05)$. However, there was no statistical difference of insulin dosages between the two groups from 24 months after diagnosis.

\section{Genetic and immunological studies}

Table 2 indicates the changes of positive rates for ICA during 36 months after diagnosis in the two groups. Within 12 months after diagnosis, the incidence of positive ICA revealed 58\% in Group A and 69\% in Group B. During 12 to 36 months, they decreased to $33 \%$ in Group A and 40\% in Group B. There was no statistical difference of ICA positivity between the two groups through the course of the study.

The frequencies of HLA phenotypes were determined among patients in the two groups, and these were compared with those of 250 normal subjects [10] and again within each group (Table 3 ). The antigen frequencies of DR3 and DRW9 were significantly higher in the 40 diabetic patients than those in normal subjects (DR3: $p<0.025$, DRW9: $p<0.01$ ). HLA DRW9 and DR4 were significantly more common in Group A than in Group B and normal subjects (vs Group B: $p<0.01$, vs normal subjects: $p<0.01$ ). There was no statistical difference in frequency of HLA DR3 between the two diabetic groups.

\section{Discussion}

It has been reported that in most patients with juvenile onset Type 1 diabetes the onset is acute and characterised by weight loss, polyuria and polydipsia often leading to ketoacidosis and impaired consciousness, and B-cell function is drastically reduced or absent at diagnosis [1, 2]. However, Ludvigsson et al. [4] found near-normal values of postprandial CPR in 5 out of 12 children with newly diagnosed Type 1 diabetes and some of them continued their B-cell capacities during the first 9 months after diagnosis. Sochett et al. [5] indicated that 17 out of 33 children with Type 1 diabetes maintained enough B-cell function for the first year of diabetes. They suggested that two groups with regard to the capacity for endogenous insulin existed in Type 1 diabetes - low and high insulin secretions.

In the present study, we examined the clinical course during the first three years of diabetes in 40 Japanese children with Type 1 diabetes, 21 patients with abrupt onset (Group A) and 19 patients detected by urine glucose screening at school (Group B). Group A patients exhibited typical symptoms of diabetes, and they showed low or undetectable values of S-CPR at diagnosis. There was an evident remission period from 3 to 9 months after treatment, but they lost
Table 1. Clinical and biochemical features of patients in groups A and $B$ at diagnosis. Numbers in parentheses indicate the number of patients studied

\begin{tabular}{|c|c|c|c|c|c|}
\hline & $\begin{array}{l}\text { Sex } \\
\text { Males/ } \\
\text { Females }\end{array}$ & $\begin{array}{l}\text { Age } \\
(y x)\end{array}$ & $\begin{array}{l}\text { HbAIC } \\
(\%)\end{array}$ & $\begin{array}{l}2 \mathrm{~h} \text { postpran- } \\
\text { dial S-CPR } \\
(\mathrm{ng} / \mathrm{ml})\end{array}$ & $\begin{array}{l}\text { Initial in- } \\
\text { sulin dosage } \\
\left(\mathrm{U} \cdot \mathrm{kg}^{-1}\right. \\
\left.\text { day }^{-1}\right)\end{array}$ \\
\hline $\begin{array}{l}\text { Group A } \\
(n=21)\end{array}$ & $12 / 9$ & $10.80 \pm 2.93$ & $\begin{array}{c}9.88 \pm 3.66 \\
(11)\end{array}$ & $\left.\begin{array}{c}0.84 \pm 0.42 \\
\mathrm{a} \quad(13)\end{array}\right] \mathrm{b}$ & $\mathrm{b} \quad \begin{array}{c}0.69 \pm 0.36 \\
(21)\end{array}$ \\
\hline $\begin{array}{l}\text { Group B } \\
(n=19)\end{array}$ & $6 / 13$ & $10.74 \pm 2.99$ & $\begin{array}{l}7.05 \pm 1.49 \\
\quad(14)\end{array}$ & $\begin{array}{c}2.56 \pm 1.15 \\
\text { (14) }\end{array}$ & $\begin{array}{l}0.25 \pm 0.25\rfloor \\
\quad(19)\end{array}$ \\
\hline
\end{tabular}

a $p<0.025 ;{ }^{b} p<0.01$

Group A: Type 1 (insulin-dependent) diabetes with abrupt onset Group B: Type 1 diabetes detected by urine glucose screening at school

Table 2. Changes in frequences of positive islet cell antibodies (ICA) during duration of diabetes in groups A and B. Numbers in parentheses indicate the percentages of ICA positive patients in the groups

\begin{tabular}{lll}
\hline Duration of diabetes (months) & $<12$ & $12-36$ \\
\hline Group A & $7 / 12(58)$ & $5 / 15(33)$ \\
Group B & $9 / 13(69)$ & $4 / 10(40)$ \\
\hline
\end{tabular}

Table 3. Comparison of percent frequencies of human leukocyte antigen phenotypes in groups A and B. Statistical differences among the two groups are expressed at bottom of figure

\begin{tabular}{llllll}
\hline & & BW54 & DR3 & DR4 & DRW9 \\
\hline Group A & $(n=17)$ & 35.3 & 5.9 & 76.5 & 70.6 \\
Group B & $(n=15)$ & 26.7 & 6.7 & 33.3 & 33.3 \\
Total & $(n=32)$ & 31.2 & 6.3 & 56.3 & 53.1 \\
Control subjects & $(n=250)$ & 19.2 & 0.4 & 40.4 & $28.0(\%)$ \\
A/B & & & $\mathrm{c}$ & $\mathrm{c}$ \\
A/Control subjects & $\mathrm{b}$ & $\mathrm{a}$ & $\mathrm{c}$ & $\mathrm{c}$ \\
B/Control subjects & & $\mathrm{b}$ & & \\
Total/Control subjects & & $\mathrm{b}$ & & $\mathrm{c}$ \\
\hline
\end{tabular}

${ }^{\mathrm{a}} p<0.05 ;{ }^{\mathrm{b}} p<0.025 ;{ }^{\mathrm{c}} p<0.01$

their B-cell faculties in a relatively short term after this period. On the other hand, Group B patients showed minimal or no symptoms of diabetes at diagnosis. They maintained near-normal values of S-CPR at diagnosis and 6 of these children required no insulin treatment at diagnosis. They maintained enough B-cell capacities until 24 months after diagnosis. Their ability for endogenous insulin gradually declined, and at examination 36 months after diagnosis, there was no statistical difference of S-CPR values between the two groups. These clinical findings indicate that there are two different clinical forms in Japanese children with Type 1 diabetes, i. e. an abrupt onset form with a post-initial remission period and a slow onset form.

It might be possible that Group B patients are not Type 1 diabetes, but Type 2 diabetes. However, all the patients in Group B failed to improve their glucose tolerance in spite of strict dietary control and physical exercise. They required insulin treatment for the control of blood glucose levels by at least 18 months after diag- 
nosis. In addition, the ICA positive rate in Group B was $69 \%$ within 12 months and $40 \%$ between 12 to 36 months after diagnosis, and there was no statistical difference for ICA positivity compared with that in patients with abrupt onset. Some previous reports indicated that the incidence of positive ICA in Type 2 diabetes was less than $3 \%[11,12]$. These results indicate that Group B, the slow onset form, is considered to be one of the sub-types of Type 1 diabetes.

Current evidence has indicated that chronic autoimmune mechanism induces pancreatic B-cell destruction in Type 1 diabetes. It has been reported that there is a pre-clinical period that precedes the development of overt diabetes by at least two or three years $[13,14]$. At the time of a pre-clinical period, the progression of Bcell destruction is relatively mild, and individuals with pre-clinical state continue to display considerable residual B-cell capacities. In the present study, our patients in Group B might be at a pre-clinical period prior to the abrupt onset of the disease. Consequently, it may be possible that the slow onset form is the same disease as the abrupt onset form but is being identified at a preclinical period.

On the other hand, with regard to HLA phenotypes, Group A patients showed significantly higher prevalence of HLA DR4 and DRW9 than Group B patients and normal control subjects. This finding suggests that genetic background may affect the progression of diabetes in early phase.

Ludvigsson et al. [15] reported that patients with HLA DR3 more often had mild symptoms at diagnosis and a subsequent partial remission than patients without this marker. In our study, there was no statistical difference in frequency of HLA DR3 between the abrupt onset form and the slow onset form. However, in Japan, the incidence of HLA DR3 in diabetic population, as well as in general population, is considerably low compared with that in Caucasian, African and Mediterranean populations [10, 15]. Consequently, it seemed unjustifiable to compare our results of HLA DR3 with those of the other countries.

In conclusion, the present study indicates that the onset and the progression of the early phase of Type 1 diabetes is quite variable. In some patients the disease progresses rapidly with definite clinical symptoms (the abrupt onset form), and others are identified by urine glucose screening at a pre-clinical period with no symptoms of diabetes (the slow onset form). It may be probable that genetic background as well as enviromental factors affect the clinical features in the early phase of Type 1 diabetes of children.

Acknowledgements. The authors are grateful to Prof. Z.Laron and Prof. M.Karp of the Institute of Pediatric and Adolescent Endocrinology, Beilinson Medical Center, Israel for their helpful advise, and Mrs. Y. Gindsberg and Ms. M.Aso for their editorial assistance. This work was supported in part by grants from the Ministry of Health and Welfare in Japan and from Japan IBM Co., Tokyo, Japan, for the research on childhood diabetes.

\section{References}

1. Ehrlich RM (1974) Diabetes mellitus in childhood. Pediatr Clin N Am 21: 871-884

2. Eberhardt MS, Wagerner DK, Orchard TJ, LaPorte RE, Cavender DE, Rabin BS, Atchison RW, Kuller LH, Drach AL, Decker BJ (1985) HLA heterogeneity of insulin-dependent diabetes mellitus at onset. Diabetes 34: 1247-1252

3. Ludvigsson J, Heding LG (1976) C-peptide in children with juvenile diabetes. Diabetologia 12: 627-630

4. Ludvigsson J, Heding LG (1978) Beta cell function in children with diabetes. Diabetes 27: 230-234

5. Sochett EB, Daneman D, Clarson C, Ehrlich RM (1987) Factors affecting and patterns of residual insulin secretion during the first year of the Type 1 (insulin-dependent) diabetes mellitus in children. Diabetologia 30: 453-459

6. Kitagawa T, Mano T, Fujita H, Tsukasa S, Hanaoka Y (1986) Prognosis of chemical diabetes in Japanese children. In: Laron Z, Karp M (eds) Future trends in juvenile diabetes - therapy and research. Pediatric and adolescent endocrinology, vol 15. Karger, Basel, pp 300-307

7. Kitagawa T, Fujita H, Tsukasa S, Hanaoka Y, Urakami T (1987) Early phase of juvenile IDDM - Environmental and genetic intervention. Acta Paediatr Jpn 29: 47-53

8. Terasaki PI (1980) HLA-DR joint report. In: Terasaki PI (ed) Histocompatibility testing. UCLA Tissue Typing Laboratory, Los Angeles, CA, pp 506

9. Neufeld M, Maclaren NK, Riley WJ, Lezotte D, McLaughlin JV, Silverstein J, Rosenbloom AL (1980) Islet cell and other organspecific antibodies in US Caucasians and Blacks with IDDM. Diabetes 29: 589-592

10. Kida K, Mimura G, Kobayashi T, Nakamura K, Sonoda S, Inoue $\mathrm{H}$, Tsuji $\mathrm{K}$ (1987) The study of HLA, ICA and autoantibodies in Japanese type 1 diabetes mellitus. Acta Paediatr Jpn 29: 345-348

11. Kobayashi T, Sugimoto T, Itoh T, Kosaka K, Tanaka T, Suwa S, Sato K, Tsuji K (1986) The prevalence of islet cell antibodies in Japanese insulin-dependent and non-insulin-dependent diabetic. patients studied by indirect immunofluorescence and a new method. Diabetes 35: 335-340

12. Kobayashi T, Sawano $S$, Itoh T, Sugimoto T, Takahashi S, Tanaka $T$, Suwa $S$ (1982) Islet cell antibodies in insulin-dependent and non-insulin-dependent diabetics in Japan: their prevalence and clinical significance. In: Mimura G, Baba S, Gatoh Y, Kobberling I (eds) Clinico-genetic genesis of diabetes mellitus. Excerpta Medica, Int. Congress Series No. 597, pp 150-160

13. Srinkata S, Ganda OP, Jackson RA, Gleason RE, Kaldany A, Garovoy MR, Milford EL, Carpenter CB, Soeldner JS, Eisenbarth GS (1984) Type 1 diabetes mellitus in monozygotic twins; chronic progressive beta cell dysfunction. Ann Intern Med 99: 320-326

14. Rabinowe SL, Eisenbarth GS (1984) Type 1 diabetes mellitus: a chronic autoimmune disease? Pediatr Clin N Am 31: 531-543

15. Ludvigsson J, Samuelsson U, Beauforts C, Deschamps I, Dorchy H, Drash A, Francois R, Herz G, New M, Schober E (1986) HLA DR3 is associated with a more slowly progressive form of Type 1 (insulin-dependent) diabetes. Diabetologia 29: 207-210

Received: 2 September 1988

and in revised form: 6 March 1989

T. Urakami, M.D.

Department of Paediatrics

Nihon University

School of Medicine

1-8-13, Kandasurugadai, Chiyoda-ku

Tokyo

Japan 